\title{
Mesorhizobium camelthorni sp. nov., isolated from Alhagi sparsifolia
}

\author{
Correspondence \\ Ge-Hong Wei \\ weigehong@yahoo.com.cn
}

\author{
Wei-Min Chen, ${ }^{1}$ Wen-Fei Zhu, ${ }^{1}$ Cyril Bontemps, ${ }^{2}$ J. Peter W. Young ${ }^{2}$ \\ and Ge-Hong Wei ${ }^{1}$ \\ ${ }^{1}$ College of Life Sciences, Shaanxi Key Laboratory of Molecular Biology for Agriculture, Northwest \\ A \& F University, Yangling, Shaanxi 712100, PR China \\ ${ }^{2}$ Department of Biology, University of York, PO Box 373, York YO10 5YW, UK
}

\begin{abstract}
Nine strains isolated from symbiotic root nodules on Alhagi sparsifolia were previously designated as representing genospecies I. Phylogenetic analyses indicated that genospecies I was related closely to Mesorhizobium alhagi (genospecies II), and clearly formed a new lineage within the genus Mesorhizobium. In this study, we differentiated genospecies I from recognized species of the genus Mesorhizobium based on phylogenetic analyses of additional core genes $(\operatorname{rec} A, g \ln A)$, levels of DNA-DNA relatedness $(<43.3 \%)$, fatty acid profile ( $58 \% \mathrm{C}_{18: 1} \omega 7 c, 19 \% 11$-methyl $\left.\mathrm{C}_{18: 1} \omega 7 \mathrm{c}\right)$, and biochemical and physiological characteristics. The nine strains are therefore considered to represent a novel species of the genus Mesorhizobium, for which the name Mesorhizobium camelthorni sp. nov. is proposed. The type strain is CCNWXJ 40-4 ${ }^{\top}$ (=HAMBI $3020^{\top}=$ ACCC $14549^{\top}$ ).
\end{abstract}

The Xinjiang Autonomous Region of north-west China includes many areas with very poor soils and dry climatic conditions, such as the Taklamakan and Gurbantünggüt deserts. Despite the harsh conditions for plant growth in these areas, the legume Alhagi sparsifolia is well adapted to these arid zones. Its success relies in part on its vigorous root system, which can thrive and spread rapidly in many types of soils including sandy, clayey and alkaline and can reach up to $15 \mathrm{~m}$ below the soil surface to tap into the water table (Sprent, 2001; Zeng et al., 2002; Siebert et al., 2004). As with many other legumes, another key to the ecological success of A. sparsifolia is its ability to form nitrogen-fixing symbioses with soil bacteria (generically termed rhizobia). This commensalism provides the plant with enough nitrogen to enable its growth in nitrogen-poor soils where most other plants cannot grow.

In a previous study, we characterized 33 rhizobia isolated from A. sparsifolia which fell into three genospecies based on restriction analysis and sequencing of their 16S rRNA, dnaK and dnaJ genes (Wei et al., 2009). Among them, genospecies II (11 isolates) has been described as Mesorhizobium alhagi (Chen et al., 2010). Here, we describe another group of nine isolates from the legume $A$. sparsifolia, previously defined as genospecies I, which

The GenBank/EMBL/DDBJ accession numbers for the 16S rRNA gene sequences of the nine strains reported in this paper are GU220798GU220806.

A supplementary table is available with the online version of this paper. represents a novel species of the genus Mesorhizobium based on additional data comprising sequences of two additional core genes $(\operatorname{rec} A$ and $g \ln A$ ), one additional symbiosis-related gene $($ nif $H)$, fatty acid profile, levels of DNA-DNA relatedness and numerical taxonomy based on phenotypic charcteristics, even though it shares high $16 \mathrm{~S}$ rRNA gene sequence similarity with $M$. alhagi (genospecies II).

The $16 \mathrm{~S}$ rRNA gene sequence of one representative strain from genospecies I, CCNWXJ $40-4^{\mathrm{T}}$, and of $M$. alhagi CCNWXJ12-2 $2^{\mathrm{T}}$ clustered in a new branch within the genus Mesorhizobium, and were identified as a new Mesorhizobium lineage (Wei et al., 2009; Fig. 1a). Strain CCNWXJ $40-4^{\mathrm{T}}$ shared $99.4 \%$ sequence similarity with M. alhagi CCNWXJ12-2 ${ }^{\mathrm{T}}$ and less than $97.8 \%$ with the type strains of other recognized species of the genus Mesorhizobium.

For three representative strains of genospecies I, the recA, $g \ln A$ and $n i f H$ genes were amplified and sequenced (Turner \& Young, 2000; Gaunt et al., 2001; Laguerre et al., 2001), and were aligned by using CLUSTAL X v.1.81 (Thompson et al., 1997). Phylogenies were reconstructed by the neighbour-joining method with Kimura's two-parameter distance correction and 100 bootstrap replicates by using PHYLO_WIN (Galtier et al., 1996), and by the maximumlikelihood method with the GTR model and 100 bootstrap replicates by using PhyML (Guindon et al., 2005).

The phylogenetic tree based on $440 \mathrm{bp}$ of the recA gene differentiated the three novel strains clearly from 
(a)

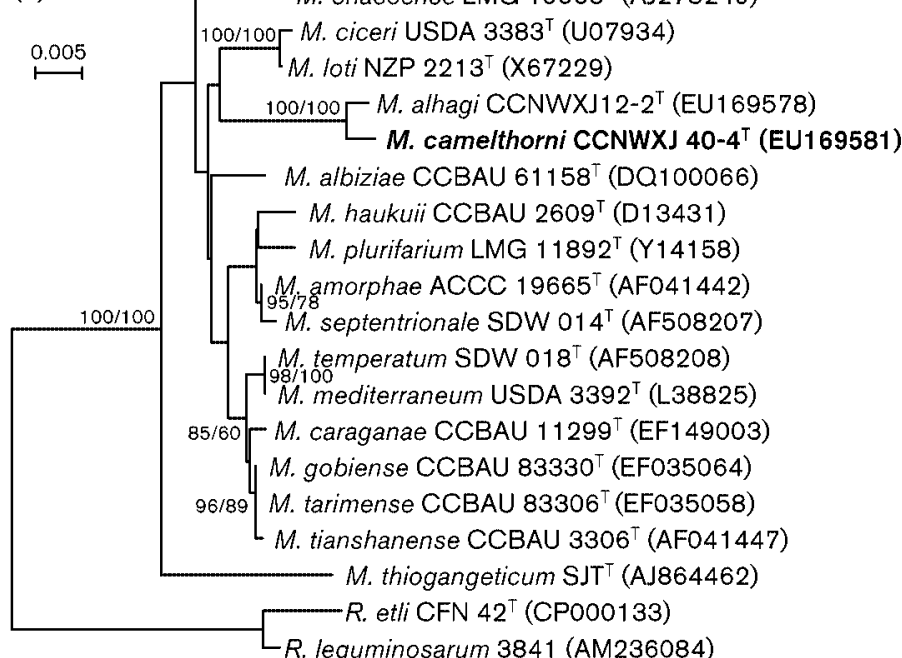

(c)

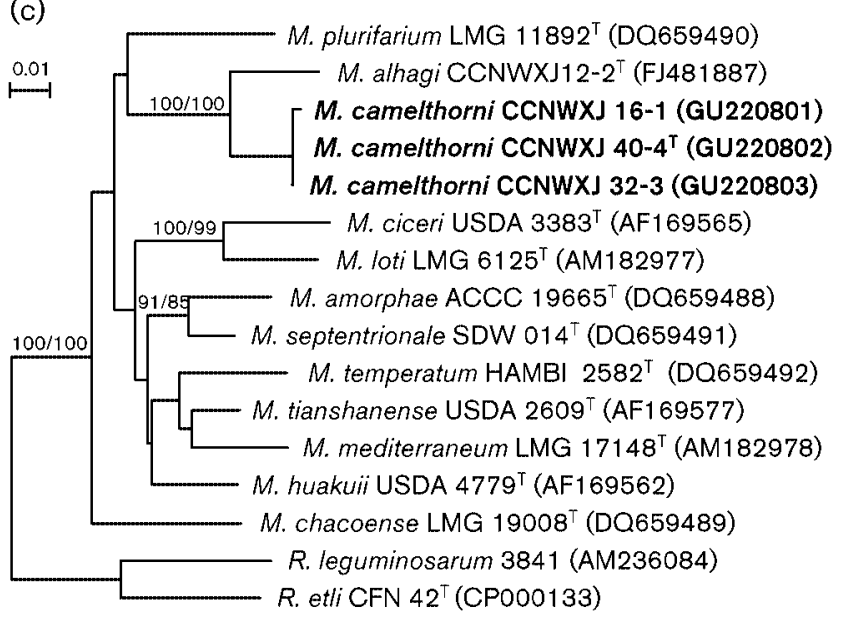

(b)

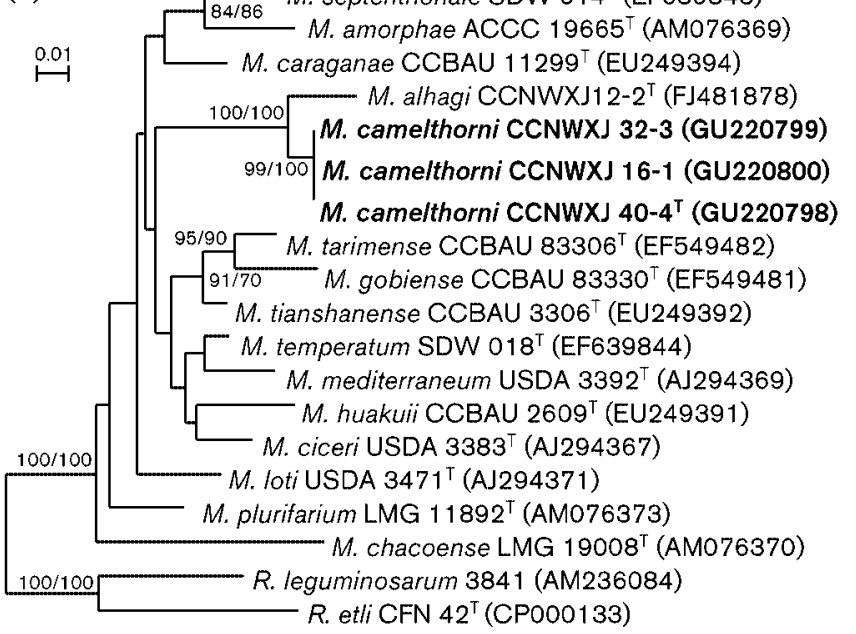

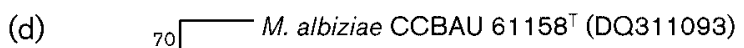

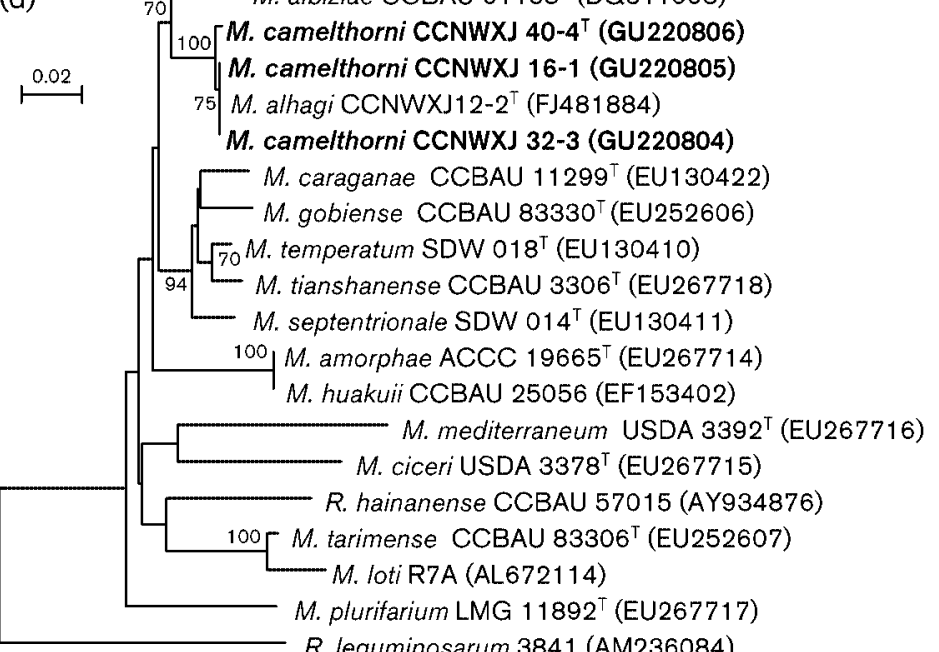

Fig. 1. Phylogenetic trees based on $16 \mathrm{~S}$ rRNA (a), recA (b), $g \ln A(\mathrm{c})$ and $n i f H(\mathrm{~d})$ gene sequences, showing the relationships among the novel isolates and recognized species of the genus Mesorhizobium. Bootstrap percentages above $70 \%$ are indicated for phylogenies reconstructed by the neighbour-joining (left) and maximum-likelihood 
recognized species of the genus Mesorhizobium (Fig. 1b), in which they formed a single clade. Strain CCNWXJ $40-4^{\mathrm{T}}$ shared $100 \% \mathrm{rec} A$ gene sequence similarity with the other two isolates (CCNWXJ 16-1 and CCNWXJ 32-3). Levels of recA gene sequence similarity with the type strains of recognized species of the genus Mesorhizobium, however, were less than $93.3 \%$ (except $97.1 \%$ with $M$. alhagi CCNWXJ12-2 ${ }^{\mathrm{T}}$ ). The tree based on $539 \mathrm{bp}$ of the $\operatorname{gln} A$ gene (Fig. 1c) was very similar: strain CCNWXJ $40-4^{\mathrm{T}}$ shared $100 \% \operatorname{gln} A$ gene sequence similarity with strain CCNWXJ 32-3, 99.8\% with strain CCNWXJ 16-1 and $96.2 \%$ with $M$. alhagi CCNWXJ12-2 ${ }^{\mathrm{T}}$, but only $90.7-$ $93.3 \%$ with the type strains of other species of the genus Mesorhizobium.

Sequence determination of the nodA and nodC genes was described previously (Wei et al., 2009); most A. sparsifolia symbionts harboured closely related nodA and nodC genes that formed a new lineage with $M$. alhagi CCNWXJ12-2 ${ }^{\mathrm{T}}$. The nifH gene encodes part of the enzyme nitrogenase, a key enzyme necessary for nitrogen fixation in rhizobia that allows them to form symbioses with legumes. Based on nifH gene sequence analysis, the three novel genospecies I strains were intermingled with those of $M$. alhagi in a wellsupported clade (100\% bootstrap support) that did not include any other of the database sequences investigated (Fig. 1d). This result differed from those observed with housekeeping gene phylogenies in which genospecies I and $M$. alhagi were always found in distinct clades. This incongruence between housekeeping genes and a symbiosis-related gene suggests the potential for nifH lateral gene transfer between genospecies I and $M$. alhagi, as previously suggested for the nodulation genes (Wei et al., 2009).

Total DNA was extracted from the nine test strains and reference strains by using the method of Marmur (1961). The DNA G $+\mathrm{C}$ content was measured by using the thermal denaturation method of Marmur \& Doty (1962) and Escherichia coli K-12 as standard. Levels of DNA-DNA relatedness were determined by using the spectrophotometric method of De Ley et al. (1970). DNA-DNA hybridization was carried out at $100{ }^{\circ} \mathrm{C}$ for denaturation and $78{ }^{\circ} \mathrm{C}$ for renaturation. The DNA G $+\mathrm{C}$ content of strain CCNWXJ 40-4 $4^{\mathrm{T}}$ was $63.7 \mathrm{~mol} \%$ (Table 1), within the range reported for recognized species of the genus Mesorhizobium (59-64 mol\%) (Jarvis et al., 1997), and the $T_{\mathrm{m}}$ value was $79.6{ }^{\circ} \mathrm{C}$. Levels of DNA-DNA relatedness between strain CCNWXJ $40-4^{\mathrm{T}}$ and other genospecies I strains ranged from 91.4 to $99.6 \%$, but were less than $43.3 \%$ with the type strains of recognized species of the genus Mesorhizobium (37.9\% with M. alhagi CCNWXJ12$2^{\mathrm{T}}$ ). Therefore, the strains in genospecies I can be regarded as representing a single novel species even though they were closely related to $M$. alhagi in the phylogenetic tree based on 16S rRNA gene sequences.

Fatty acid methyl esters were extracted and measured for strain CCNWXJ 40-4 ${ }^{\mathrm{T}}, M$. alhagi CCNWXJ12-2 ${ }^{\mathrm{T}}, M$. ciceri USDA $3383^{\mathrm{T}}$ and M. loti NZP $2213^{\mathrm{T}}$ by using a standard protocol (see Supplementary Table S1 in IJSEM Online). The results indicated that strain CCNWXJ $40-4^{\mathrm{T}}$ should be assigned to the genus Mesorhizobium as it lacked $\mathrm{C}_{20: 3} \omega 6,9,12 c$ and summed feature 3 (one or more of $\mathrm{C}_{12: 0}$ aldehyde, unknown ECL 10.928, iso- $\mathrm{C}_{16: 1} \mathrm{I}$ and/or $\left.\mathrm{C}_{14: 0} 3-\mathrm{OH}\right)$ and possessed iso- $\mathrm{C}_{17: 0}$ fatty acids (Tighe et al., 2000). Strain CCNWXJ $40-4^{\mathrm{T}}$ differed from recognized species of the genus Mesorhizobium in containing higher concentrations of $\mathrm{C}_{18: 1} \omega 7 c$.

In total, 125 phenotypic characteristics covering utilization of sole carbon and nitrogen sources, resistance to antibiotics, tolerance to dyes and other chemicals, tolerance to different concentrations of $\mathrm{NaCl}$, temperature and $\mathrm{pH}$ ranges for growth, and other characteristics useful for diagnostic purposes with rhizobia were tested for the novel strains. Phenotypic characteristics were analysed by the unweighted pair group method with arithmetic averages (UPGMA) (Sneath \& Sokal, 1973). Based on the results of cluster analysis (Fig. 2), the nine isolates from A. sparsifolia formed one group while the reference strains were grouped according to species at a similarity level of $76.5 \%$. The mean similarity for the isolates ranged from $82.0 \%$ for strain CCNWXJ $32-3$ to $98.0 \%$ for strain CCNWAX 25-1. Differential characteristics between strain CCNWXJ $40-4^{\mathrm{T}}$ and its closest relatives are shown in Table 2 and further features are presented in the species description below.

In nodulation tests, all nine test strains formed pink nodules on the roots of $A$. sparsifolia, which indicated that the nodules were effective in fixing nitrogen, and no nodules formed on the uninoculated control plants in any experiment. In cross-infection tests with legumes that can be found in the sampling areas, strain CCNWXJ $40-4^{\mathrm{T}}$ was able to nodulate Sophora alopecuroides, Glycyrrhiza inflate and Medicago sativa, but not Indigofera endecaphylla, Vicia cracca or Sophora flavescens. This indicates that strain CCNWXJ $40-4^{\mathrm{T}}$ has a narrow host range compared with $M$. alhagi, even though the two taxa have similar nodA and nodC genes.

\section{Description of Mesorhizobium camelthorni sp. nov.}

Mesorhizobium camelthorni (ca.mel.thor'ni. N.L. n. camelthornum camelthorn, a common name for leguminous plants of the genus Alhagi in China; N.L. gen. n. camelthorni of camelthorn, from which the type strain was isolated).

Gram-negative, aerobic, motile, non-spore-forming rods, $0.3-0.6 \mu \mathrm{m}$ wide by $1.0-1.2 \mu \mathrm{m}$ long. Colonies on yeast extract-malt extract agar (YMA) are white, opaque, circular and convex with diameter of 1-2 $\mathrm{mm}$ within 5-7 days at $28{ }^{\circ} \mathrm{C}$; generation time ranges from 4.8 to $6.6 \mathrm{~h}$. The optimum temperature and $\mathrm{pH}$ for growth are $28{ }^{\circ} \mathrm{C}$ and $\mathrm{pH}$ 7. Unable to grow on YMA at $\mathrm{pH} 5.0$ or $\mathrm{pH} 12.0$ or at 
Table 1. Levels of DNA-DNA relatedness among strains representing the candidate species and the type strains of some recognized species in the genus Mesorhizobium

Data from this study. ND, Not determined.

\begin{tabular}{|c|c|c|c|c|c|}
\hline Strain & Host plant & Geographical origin & $T_{\mathrm{m}}\left({ }^{\circ} \mathrm{C}\right)$ & $\begin{array}{c}\text { DNA G }+ \text { C content } \\
(\mathrm{mol} \%)\end{array}$ & $\begin{array}{l}\text { DNA-DNA relatedness } \\
\text { with strain } \\
\text { CCNWXJ40-4 }^{\mathrm{T}}(\%)\end{array}$ \\
\hline CCNWXJ $40-4^{\mathrm{T}}$ & Alhagi sparsifolia & Alaer, Xinjiang, China & 79.6 & 63.7 & 100 \\
\hline CCNWXJ 16-1 & Alhagi sparsifolia & Alaer, Xinjiang, China & 79.0 & 62.4 & 97.4 \\
\hline CCNWXJ 32-3 & Alhagi sparsifolia & Alaer, Xinjiang, China & 79.2 & 62.9 & 95.5 \\
\hline CCNWXJ 26-3 & Alhagi sparsifolia & Alaer, Xinjiang, China & 78.6 & 61.6 & 91.4 \\
\hline CCNWXJ 34-1 & Alhagi sparsifolia & Alaer, Xinjiang, China & 79.5 & 63.6 & 99.6 \\
\hline CCNWXJ 38-1 & Alhagi sparsifolia & Alaer, Xinjiang, China & 77.4 & 59.5 & 98.7 \\
\hline CCNWAX 41-1 & Alhagi sparsifolia & Anxi, Gansu, China & 77.8 & 59.9 & 93.5 \\
\hline CCNWAX 25-1 & Alhagi sparsifolia & Anxi, Gansu, China & 78.4 & 61.2 & 92.4 \\
\hline M. alhagi CCNWXJ12-2 ${ }^{\mathrm{T}}$ & Alhagi sparsifolia & Alaer, Xinjiang, China & 78.0 & 60.4 & 37.9 \\
\hline M. plurifarium LMG $11892^{\mathrm{T}}$ & Acacia senegal & Senegal & ND & ND & 25.8 \\
\hline M. amorphae ACCC $19665^{\mathrm{T}}$ & Amorpha fruticosa & Beijing, China & ND & ND & 3.8 \\
\hline M. huakuii CCBAU $2609^{\mathrm{T}}$ & Astragalus sinicus & Nanjing, China & $\mathrm{ND}$ & ND & 23.6 \\
\hline M. chacoense LMG $19008^{\mathrm{T}}$ & Prosopis alba & Argentina & ND & ND & 37.0 \\
\hline M. mediterraneum USDA $3392^{\mathrm{T}}$ & Cicer arietinum & Spain & $\mathrm{ND}$ & $\mathrm{ND}$ & 16.3 \\
\hline M. tianshanense CCBAU $3306^{\mathrm{T}}$ & Glycyrrhiza uralensis & Xinjiang, China & $\mathrm{ND}$ & $\mathrm{ND}$ & 25.7 \\
\hline
\end{tabular}

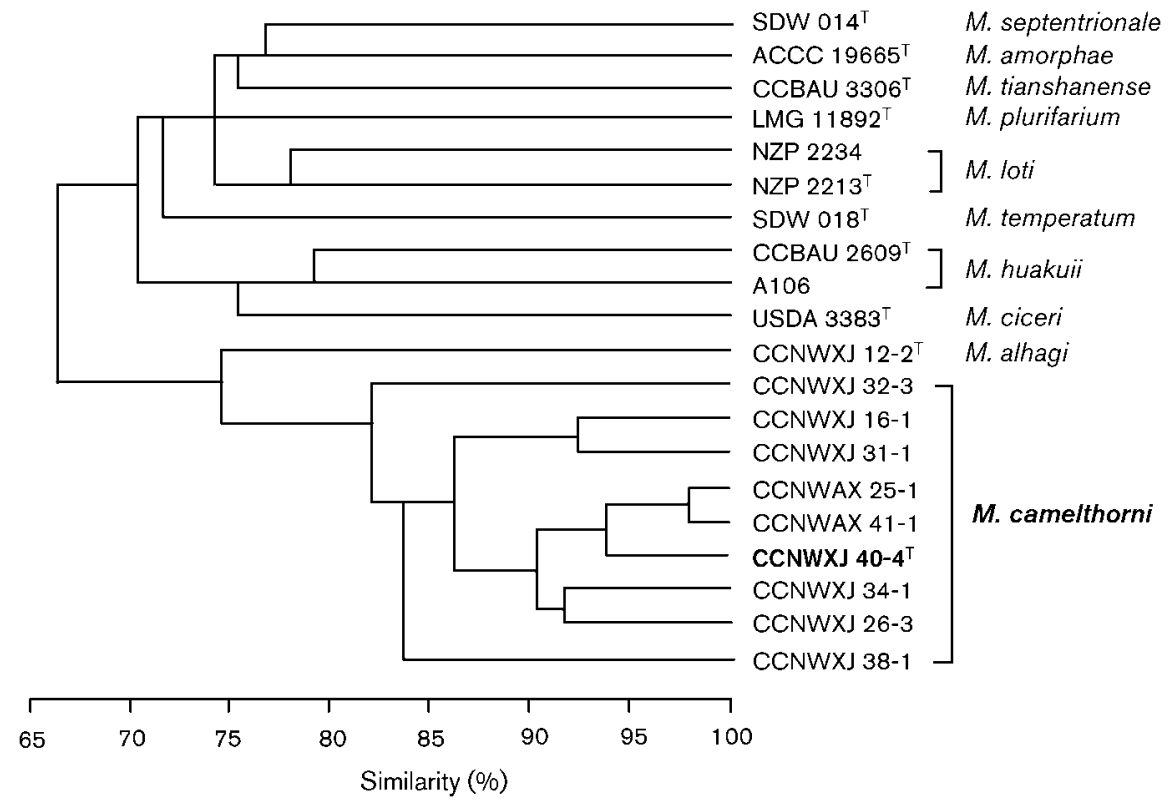

Fig. 2. Dendrogram based on the results of numerical taxonomy showing the phenotypic similarities among the novel isolates and reference strains representing species of the genus Mesorhizobium. Clustering analysis was performed by using the UPGMA method. 
Table 2. Differential characteristics between strain CCNWXJ 40-4 ${ }^{\top}$ and closely related species of the genus Mesorhizobium

Strains: 1 , CCNWXJ 40-4 ${ }^{\mathrm{T}} ; 2$, M. alhagi CCNWXJ12-2 $2^{\mathrm{T}} ; 3$, M. ciceri USDA $3383^{\mathrm{T}} ; 4$, M. loti NZP $2213^{\mathrm{T}}$. Data from this study.

\begin{tabular}{|c|c|c|c|c|}
\hline Characteristic & 1 & 2 & 3 & 4 \\
\hline \multicolumn{5}{|l|}{ Utilization as sole carbon source } \\
\hline Sodium citrate & + & + & - & - \\
\hline L-Rhamnose & + & + & + & + \\
\hline D-Xylose & + & + & + & - \\
\hline D-Fructose & + & + & + & - \\
\hline D-Sorbitol & + & + & + & + \\
\hline D-Arabinose & + & + & + & - \\
\hline Inositol & + & + & + & + \\
\hline Maltose & + & + & + & + \\
\hline Sodium succinate & + & + & + & + \\
\hline Sodium hippurate & - & - & - & - \\
\hline Melibiose & - & - & - & - \\
\hline Sodium tartrate & - & - & - & - \\
\hline \multicolumn{5}{|l|}{ Utilization as sole nitrogen source } \\
\hline D-Arginine & - & + & + & + \\
\hline D-Aspartate & - & - & + & + \\
\hline L-Cystine & + & + & + & + \\
\hline L-Lysine & + & + & + & + \\
\hline L-Phenylalanine & + & + & + & + \\
\hline DL-Histidine & - & - & - & - \\
\hline Glycine & + & + & - & - \\
\hline \multicolumn{5}{|l|}{ Growth at/with: } \\
\hline pH 5 & - & - & + & - \\
\hline $\mathrm{pH} 10$ & - & + & - & - \\
\hline $2 \% \mathrm{NaCl}$ & + & + & + & - \\
\hline \multicolumn{5}{|l|}{ Resistance to: } \\
\hline Ampicillin $\left(50 \mu \mathrm{g} \mathrm{ml}^{-1}\right)$ & - & - & - & - \\
\hline Erythromycin $\left(5 \mu \mathrm{g} \mathrm{ml}^{-1}\right)$ & + & + & + & + \\
\hline Erythromycin $\left(50 \mu \mathrm{g} \mathrm{ml}^{-1}\right)$ & - & - & + & + \\
\hline Streptomycin $\left(5 \mu \mathrm{g} \mathrm{ml}^{-1}\right)$ & - & - & + & + \\
\hline Gentamicin $\left(5 \mu \mathrm{g} \mathrm{ml}^{-1}\right)$ & - & - & + & + \\
\hline Chloramphenicol $\left(5 \mu \mathrm{g} \mathrm{ml}^{-1}\right)$ & + & + & + & - \\
\hline Neutral red $0.2 \%$ & - & - & - & + \\
\hline Bromothymol blue $0.2 \%$ & - & - & + & - \\
\hline
\end{tabular}

$10{ }^{\circ} \mathrm{C}$. Utilizes sodium citrate, L-rhamnose, D-xylose, Dfructose, D-sorbitol, D-arabinose, inositol and sodium succinate, but not sodium hippurate, DL-histidine, melibiose, sodium tartrate or D-arginine. Unable to grow on YMA supplemented with methylene blue, malachite green, methyl green or methyl red. Sensitive to streptomycin, gentamicin sulfate and amikacin sulfate, but tolerant to erythromycin and gentamicin (all at $5 \mu \mathrm{g} \mathrm{ml}^{-1}$ ). Able to grow on YMA in the presence of $2 \%(\mathrm{w} / \mathrm{v}) \mathrm{NaCl}$. The DNA $\mathrm{G}+\mathrm{C}$ content is $59.5-63.7 \mathrm{~mol} \%$. Can be differentiated clearly from other species of the genus Mesorhizobium by both genetic and phenotypic methods, including sequences of core genes (16S rRNA, recA and $g \ln A$ ), fatty acid composition and levels of DNA-DNA relatedness.

The type strain, CCNWXJ $40-4^{\mathrm{T}} \quad$ (=HAMBI $3020^{\mathrm{T}}$ $=$ ACCC $14549^{\mathrm{T}}$ ), was isolated from a root nodule of $A$. sparsifolia in Alaer, Xinjiang Province, China. The DNA $\mathrm{G}+\mathrm{C}$ content of strain CCNWXJ $40-4^{\mathrm{T}}$ is $63.7 \mathrm{~mol} \%$.

\section{Acknowledgements}

This work was supported by projects from the National Science Foundation of China $(30970003,30900215)$ and National Basic Research Program of China (2010CB126502). We are grateful to Professor Kristina Lindström, HAMBI, and Professor Ruibo Jiang, ACCC, for deposition of the strain in the culture collections.

\section{References}

Chen, W.-M., Zhu, W.-F., Young, J. P. W., Bontemps, C. \& Wei, G. H. (2010). Mesorhizobium alhagi sp. nov., isolated from wild Alhagi sparsifolia in north-western China. Int J Syst Evol Microbiol 60, 958962.

De Ley, J., Cattoir, H. \& Reynaerts, A. (1970). The quantitative measurement of DNA hybridization from renaturation rates. Eur $J$ Biochem 12, 133-142.

Galtier, N., Gouy, M. \& Gautier, C. (1996). SEAVIEW and PHYLO_WIN: two graphic tools for sequence alignment and molecular phylogeny. Comput Appl Biosci 12, 543-548.

Gaunt, M. W., Turner, S. L., Rigottier-Gois, L., Lloyd-Macgilp, S. A. \& Young, J. P. W. (2001). Phylogenies of atpD and recA support the small subunit rRNA-based classification of rhizobia. Int J Syst Evol Microbiol 51, 2037-2048.

Guindon, S., Lethiec, F., Duroux, P. \& Gascuel, O. (2005). PHYML online-a web server for fast maximum likelihood-based phylogenetic inference. Nucleic Acids Res 33 (Web Server), W557W559.

Jarvis, B. D. W., van Berkum, P., Chen, W. X., Nour, S. M., Fernandez, M. P., Cleyet-Marel, J. C. \& Gillis, M. (1997). Transfer of Rhizobium loti, Rhizobium huakuii, Rhizobium ciceri, Rhizobium mediterraneum, and Rhizobium tianshanense to Mesorhizobium gen. nov. Int J Syst Bacteriol 47, 895-898.

Laguerre, G., Nour, S. M., Macheret, V., Sanjuan, J., Drouin, P. \& Amarger, N. (2001). Classification of rhizobia based on nodC and nifH gene analysis reveals a close phylogenetic relationship among Phaseolus vulgaris symbionts. Microbiology 147, 981993.

Marmur, J. (1961). A procedure for the isolation of deoxyribonucleic acid from microorganisms. J Mol Biol 3, 208-218.

Marmur, J. \& Doty, P. (1962). Determination of the base composition of deoxyribonucleic acid from its thermal denaturation temperature. J Mol Biol 5, 109-118.

Siebert, S., Gries, D., Zhang, X., Runge, M. \& Buerkert, A. (2004). Non-destructive dry matter estimation of Alhagi sparsifolia vegetation in a desert oasis of Northwest China. J Veg Sci 15, 365372.

Sneath, P. H. A. \& Sokal, R. B. (1973). Numerical Taxonomy. The Principles and Practice of Numerical Classification. San Francisco: W. H. Freeman.

Sprent, J. I. (2001). Nodulation in Legumes. Kew: Kew Publishing.

Thompson, J. D., Gibson, T. J., Plewniak, F., Jeanmougin, F. \& Higgins, D. G. (1997). The CLUSTAL_X windows interface: flexible strategies for multiple sequence alignment aided by quality analysis tools. Nucleic Acids Res 25, 4876-4882.

Tighe, S. W., de Lajudie, P., Dipietro, K., Lindström, K., Nick, G. \& Jarvis, B. D. W. (2000). Analysis of cellular fatty acids and 
phenotypic relationships of Agrobacterium, Bradyrhizobium, Mesorhizobium, Rhizobium and Sinorhizobium species using the Sherlock Microbial Identification System. Int J Syst Evol Microbiol 50, 787-801.

Turner, S. L. \& Young, J. P. W. (2000). The glutamine synthetases of rhizobia: phylogenetics and evolutionary implications. Mol Biol Evol 17, 309-319.
Wei, G. H., Chen, W. M., Young, J. P. W. \& Bontemps, C. (2009). A new clade of Mesorhizobium nodulating Alhagi sparsifolia. Syst Appl Microbiol 32, 8-16.

Zeng, F., Zhang, X., Foetzki, A., Li, X., Li, X. \& Runge, M. (2002). Water relation characteristics of Alhagi sparsifolia and consequences for a sustainable management. Sci China Ser D: Earth Sci 45 (Suppl. 1), 125-131. 